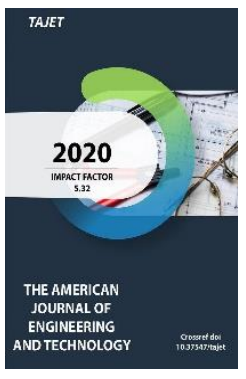

Copyright: Original content from this work may be used under the terms of the creative commons attributes 4.0 licence.

\section{Design Model Of Bending Reinforced Concrete Elements Under Action Of Transverse Forces Under Conditions Of Increased And High Temperatures}

\author{
Mahkamov Y.M. \\ Associate Professor, Candidate Of Technical Sciences, Department Construction Of Buildings \\ And Structures, Fergana Polytechnic Institute, Fergana, Uzbekistan \\ Mirzababaeva S.M. \\ Senior Lecturer, Department Of Construction Of Buildings And Structures, Fergana Polytechnic \\ Institute, Fergana, Uzbekistan
}

\title{
ABSTRACT
}

In this article, the calculation of the strength and crack resistance of bending elements operating under conditions of high and high temperatures and transverse forces are proposed to be carried out according to a calculation model developed based on an analysis of experimental studies that takes into account more correctly the physics of the stress-strain phenomenon of the element.

\section{KEYWORDS}

Bending reinforced concrete element, transverse force, bending moment, strength, crack resistance, stress, concrete, reinforcement, temperature, strength criterion.

\section{INTRODUCTION}

For bending elements operating under conditions of exposure to suspended and high technological temperatures, small spans and significant transverse forces are characteristic. Therefore, ensuring the required strength of their inclined sections is of great importance. The correct calculation of the strength of inclined sections of reinforced concrete elements operating under conditions of exposure to technological temperatures largely determines their reliability, efficiency and material consumption.

A further increase in the efficiency and durability of structures requires a deeper analysis of the resistance of reinforced concrete elements under the action of transverse forces and high temperatures and the 
development of more accurate and perfect methods for calculating the strength of their inclined sections. For this purpose, complex experimental and theoretical studies of the resistance of bending reinforced concrete elements made of ordinary and heat-resistant concrete to the action of transverse forces under conditions of exposure to high and high temperatures were carried out and proposals were developed for calculating the strength of inclined sections. At the same time, the accumulated experimental material of both the authors and other researchers was analyzed [1-5].

\section{MATERIALS AND METHODS}

The performed analysis showed that for bending reinforced concrete elements under the action of transverse forces and one-sided heating, the following is characteristic:

- Before the formation of inclined cracks, stresses in concrete on planes perpendicular to the expected inclined crack reach or exceed the value of concrete tensile resistance when heated;

- When an element is destroyed along an inclined section:

- Stresses of longitudinal reinforcement at the points of intersection with an inclined crack can reach the yield point of reinforcement when heated;

- Stresses in the clamps reach the yield point of the reinforcement, taking into account the maximum temperature of their heating;

- Stresses in the concrete of the compressed zone above the inclined crack reach the value of the resistance of concrete to compression when heated.
The change in the strength and deformative properties of concrete and reinforcement during heating has a decisive effect on the crack resistance and strength of a bending element along an inclined section.

Therefore, the main attention was paid to the establishment of design stress diagrams in concrete (Fig.1).

The stress plots in concrete under and above an inclined crack during heating are identical to the corresponding plots at normal temperature. The completeness of the stress diagram in concrete increases during heating. The diagram of normal stresses bx in concrete above an inclined crack has a curvilinear character and increases to the value Rbtem on the most compressed face of the section. Under the inclined crack, the normal stress diagram is also curvilinear: from zero, above the tip of the normal crack, it grows to Rbtem at the tip of the inclined crack. The diagram of tangents is stressed parabolic, with a maximum of $\tau$ хумах at the tip of an inclined crack. Design diagrams of tangential stresses for elements without clamps are taken in the section above normal cracks, in elements with clamps at the entire height of the section. Possible deviations of the accepted design diagrams from the actual ones are taken into account by the stress completeness coefficients $\omega i$. 
(1)

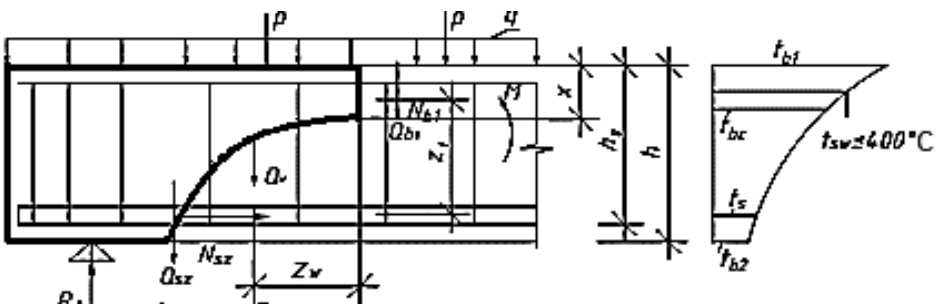

(2)
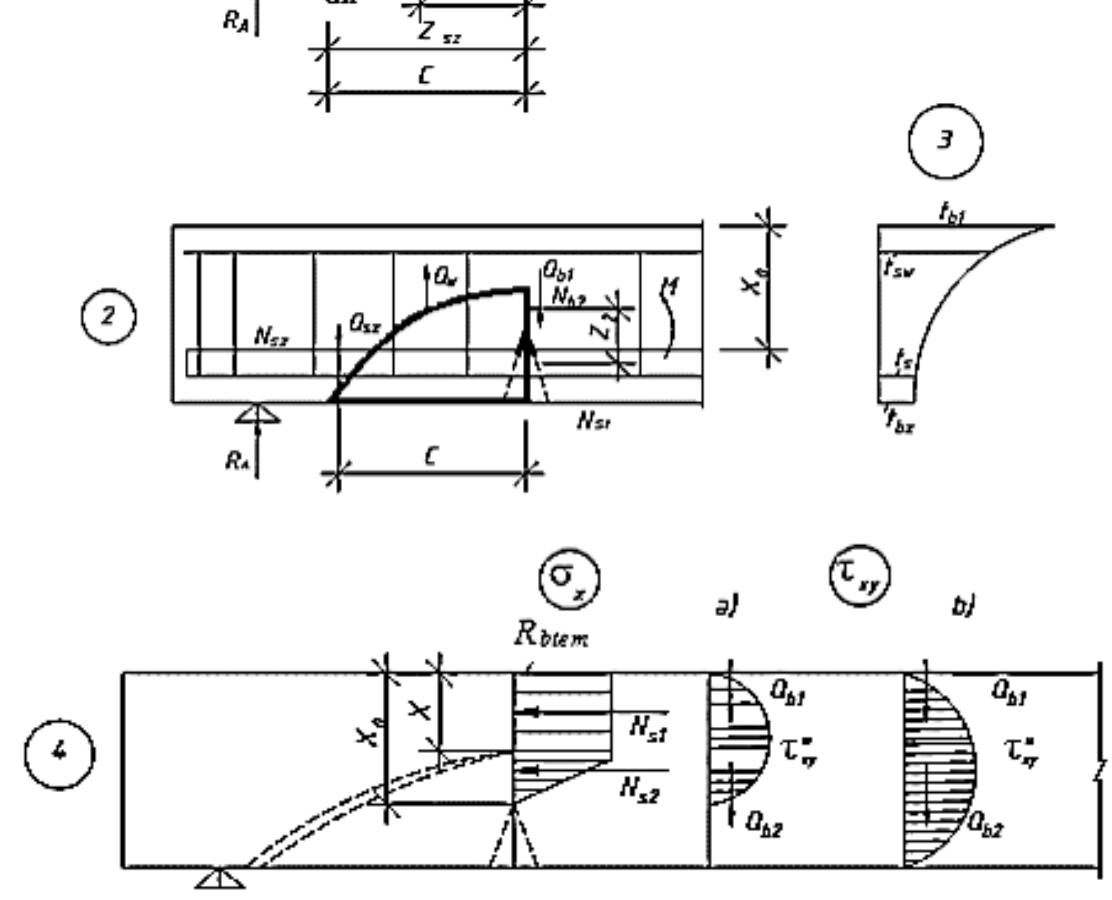

Fig. 1. The design model of a bending reinforced concrete element when calculating the action of a transverse force in conditions of high and high temperatures:

Calculations have shown that the best agreement of the experimental data with the calculated ones is achieved with the values of the coefficients $w_{1}=1, w_{2}=0,75, w_{3}=1, w_{4}=1$.

The analysis showed that the longitudinal reinforcement located on the less heated face of the section of the element plays the same role in the operation of inclined sections as at normal temperature. The relative value of the thrust resistance of the longitudinal reinforcement increases with one-sided heating. With an increase in the percentage and diameter of longitudinal reinforcement, the strength of inclined sections of beams increases with one-sided heating.
Reinforcement with clamps, including shortened ones, installed in the elements by $2 / 3 \mathrm{~h}$, where the heating temperature does not exceed $400^{\circ} \mathrm{C}$, increases the strength of the inclined sections of the bent element.

The absolute value of the transverse force perceived by the clamps when heated in the limiting state decreases slightly compared to normal temperature.

An increase in the relative span of the shear leads to a decrease in the limiting shear force perceived by the inclined section of the element before failure under conditions of exposure to high and high temperatures. The strength of inclined sections of bending 
elements under the action of transverse forces and one-sided heating depends on the form of destruction of the element along the inclined section. The bending element has the greatest strength along an inclined section when it breaks in a compressed zone from crushing or spitting out of concrete over an inclined crack and the least when the element breaks due to a violation of the adhesion of the longitudinal reinforcement to concrete and its anchoring.

Calculation of the strength of inclined sections under the action of transverse forces under conditions of one-sided heating showed that the method $[8,9]$ for bending elements made of ordinary concrete gives satisfactory agreement with experiment, and for elements made of heat-resistant concrete it underestimates their design strength. The ratio of the experienced transverse force to the theoretical one according to $[7,8]$ for beams made of ordinary concrete averaged 1.13 , for beams made of heat-resistant concrete: on alumina cement - 2.39, on Portland cement 3.46 , on liquid glass - 3.22. Such a discrepancy between the experimental and theoretical shear forces largely depends on the accepted low values of the design coefficients $\varphi_{b_{2}}$ and $\varphi_{b_{3}}$ for heat-resistant concrete.

Refinement of the values of the calculated coefficients $\varphi_{b_{2}}$ and $\varphi_{b_{3}}$ according to the experimental data depending on the average temperature of the concrete in the compressed zone and the type of concrete showed that they have a significant scatter.

However, even if calculations are made using the minimum experimental values of the

$$
\begin{gathered}
a t \sigma_{1} / R_{b t e m} \leq 0,5 \sigma_{3} / R_{b t t}=1 ; \\
a t \sigma_{1} / R_{b t e m}>0,5 \sigma_{1} / R_{b t e m}+\sigma_{3} / 2 R_{b t t}=1 ;
\end{gathered}
$$

for the area "compression - compression" calculated coefficients $\varphi_{b_{2}}$ and $\varphi_{b_{3}}$, then the convergence of the experimental and theoretical lateral forces is significantly improved. The average temperature of concrete in the compressed zone of the section is allowed to be taken according to the temperature of the concrete located at a distance of $0,2 h_{0}$ from the most compressed edge of the section.

To assess the crack resistance and strength of inclined sections of bent reinforced concrete elements operating under conditions of onesided heating, it would be necessary to use the criterion of concrete strength in a plane stressed state. The criterion of the strength of ordinary concrete in a plane stressed state under conditions of short-term heating up to $600{ }^{\circ} \mathrm{C}$, obtained by German researchers, was identical to the criterion of strength at normal temperature and depended on the strength of concrete for uniaxial compression and tension when heated.

Concretes for structures operating under heating conditions have compressive strength generally corresponding to classes B20-B30. When heated, the strength of concrete generally decreases. Based on this, in order to simplify the calculation, a unified strength criterion was adopted, obtained for concrete B25 and below at normal temperature, taking into account the decrease in the strength of concrete during heating. The calculated strength criterion for the "compression tension" region under the influence of temperature has the form: 


$$
\sigma_{1} / R_{\text {btem }}=1
$$

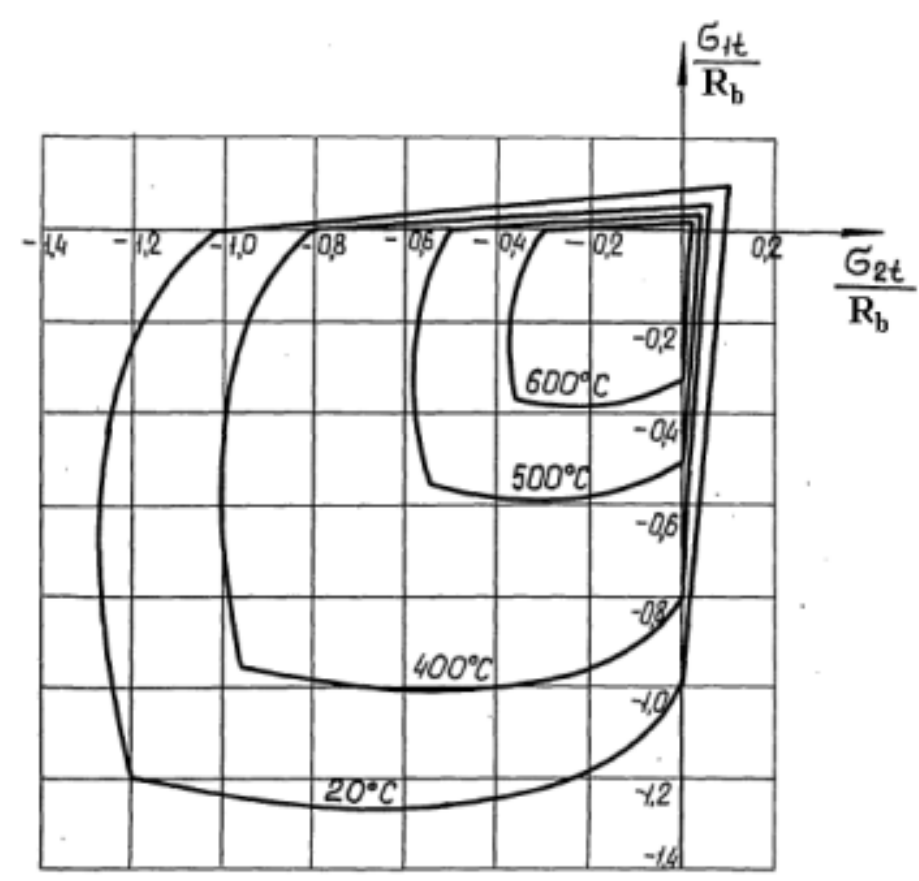

Fig. 2. Strength criterion for conventional heavy concrete based on Portland cement with quartz fillers in a plane stressed state under conditions of short-term heating [5].

Analysis of the strength of inclined sections of beams tested with one-sided heating showed that the proposed calculation method, developed for elements operating at normal temperatures, can be applied to elements operating at elevated and high temperatures. With this approach, it is ensured that a unified technique is maintained for all reinforced concrete elements. However, at the same time, it was revealed the need to take into account the change in the strength and deformation properties of concrete and reinforcement during heating and the peculiarities of the stress-strain state of a bent element under conditions of one-sided heating. A system of longitudinal and transverse forces is introduced into the design scheme of forces, in accordance with the proposed design model, of an inclined section of a bent reinforced concrete element operating under unilateral heating: in concrete above an inclined crack $N_{b_{1}}$ and $Q_{b_{1}}$, under an inclined crack $N_{b_{2}}$ and $Q_{b_{2}}$, engagement forces in inclined crack $N_{z}$ and $Q_{z}$, in longitudinal reinforcement - $N_{s}$ and $Q_{s}$; and axial forces in transverse reinforcement crossing the inclined crack - $Q_{w}$ (see Fig. 1).

The forces in the longitudinal reinforcement and the interception forces in the inclined crack are considered in the form of the total values $N_{s z}=N_{s}-N_{z}$ and $Q_{s z}=Q_{s}+Q_{z}$ applied at the point of intersection of the inclined crack by the longitudinal reinforcement. The design condition for the strength of inclined sections 
of bent reinforced concrete elements operating with unilateral heating has the form

$$
Q=Q_{w}+Q_{b 1}+Q_{b 2}
$$

The transverse force $Q_{w}$ is determined taking into account the maximum heating temperature of the clamps according to the formula

$$
Q_{w}=\sum R_{s w t} \cdot A_{w}=q_{w} \cdot c
$$

The transverse force $Q_{b 1}$ perceived by the concrete in the compressed zone above the inclined crack is determined by the formula

$$
Q_{b 1}=0,5 R_{h t} \cdot b \cdot x
$$

The transverse force $Q_{b_{2}}$, which characterizes the thrust force in the longitudinal reinforcement and the engagement forces in the inclined crack, is determined by the formula

$$
Q_{b 2}=0,7 R_{h t} \cdot b \cdot\left(x_{0}-x\right)
$$

The value of concrete shear resistance during heating $R_{h t}$ is determined depending on the concrete temperature at a distance of $0,2 h_{0}$ from the most compressed edge of the section according to the expression

$$
R_{h t=} 2,5 R_{b t} \cdot\left(1+5 \cdot \sigma_{y} / R_{b t}\right) \leq 0,5 R_{b t}
$$

where $\sigma_{y}$ - vertical stresses from the local action of the load or the support reaction.

The values of the height of the compressed zone of concrete above the normal $X_{0}$ and inclined $X$ cracks are determined by the formulas:

$$
\begin{gathered}
X_{0} h_{0}=0,5 n \mu_{s}+L^{2} / 0,5 n \mu_{s}+L ; \\
X / h_{0}=2 L-x h_{0} ;
\end{gathered}
$$

Where $n=1,5 \cdot E_{s t} / E_{b t}, L=M / R_{b t} \cdot b \cdot h_{0} \cdot Z_{1}$,

for ordinary concrete elements $Z_{1}=0,7 h_{0}$, heat-resistant concrete

$Z_{1}=0,6 h_{0}$

The length of the projection of the inclined crack " $C$ " onto the longitudinal axis of the element is determined from the equation of equilibrium of moments in the lower block under the inclined crack. If the height of the compressive zone of concrete $\mathrm{X}$ above an inclined crack, determined by the formula (10), turns out to be negative, then the bending moment and shear force that can be perceived by the section are calculated taking the calculated stress diagram in concrete over normal triangular with a maximum on the most compressed face of the section $R_{\text {btem }}$.

In this case, the height of the compressed zone Xo above normal cracks is determined as to 
when calculating the strength of normal sections.

For small values of the relative shear span $\left(0,5 \leq \alpha h_{0} \leq 1,5\right)$, the design shear force is $P=K_{b t} \cdot \gamma_{b} \cdot R_{b t e m} \cdot b \cdot I_{p} \cdot \sin \alpha,(11)$

for elements with transverse reinforcement

$$
P=\left[K_{b t} \cdot \gamma \cdot R_{b t e m} \cdot+\sum K_{s t} \cdot \gamma_{s} \cdot R_{s t} \cdot \mu_{w} \cdot \sin \alpha(\alpha+6)\right] \cdot b \cdot I_{p} \cdot \sin \alpha,(12)
$$

Where $K_{b t}=0,7, K_{s t}=0,9$ - coefficients that take into account the deviation of pleasant calculation schemes from the actual; $\gamma_{b}$ and $\gamma_{s}$ coefficients that take into account the effect of surrounding concrete and reinforcement on the strength of the inclined strip, are determined according to the rules of calculation for local collapse according to [7]; $\mu_{w}$ - transverse reinforcement coefficients; $\alpha$ is the angle of inclination of the calculated strip to the horizontal; 8 - the angle of inclination of transverse reinforcement; Ip is the calculated width of the inclined strip. The proposed design model corresponds to the real stressstrain state and the method for calculating the strength of inclined sections of bent reinforced concrete elements operating with one-sided heating have high accuracy and reliability, the essence of the phenomenon is correctly reflected and gives a better match with experience. The ratio of the experienced shear force to the theoretical for beams made of ordinary heavy concrete was 1.05 , for beams made of heat-resistant concrete - on alumina cement - 1.18, on Portland cement - 1.20 and on liquid glass - 1.23. Before the destruction of reinforced concrete beams along an inclined section with unilateral heating, the total transverse force is perceived:

- In beams without clamps: determined from the condition of the strength of short elements: for elements without transverse reinforcement
- compressed concrete over an inclined crack - 16-44\%;

- the total value of the nail forces in the longitudinal reinforcement and the forces of engagement in an inclined crack - 56$84 \%$;

- in beams with clamps:

- compressed concrete over an inclined crack - 8-33\%;

- clamps-12-51\%;

- the total value of the thrust forces of the longitudinal reinforcement and the forces of engagement in an inclined crack is 22$69 \%$.

The relative magnitude of the shear force perceived by the compressed concrete above the inclined crack during heating remains approximately the same as at normal temperature, the shear force perceived by the clamps slightly decreases, and the relative magnitude of the sum of the nail forces and engagement increases.

\section{CONCLUSION}

The developed practical recommendations for calculating the strength of inclined sections of bent reinforced concrete elements made of ordinary and heat-resistant concrete allows to more correctly estimate the design strength of an element along an inclined section, increase their reliability and durability during operation 
and ensure steel savings, reduce the cost and labour intensity of constructions and achieve a significant economic effect in the field of construction of heating units.

\section{REFERENCES}

1. Makhkamov, J.M. (1984). The resistance of bending reinforced concrete elements under the action of shear forces and high temperatures. Diss.... PhD. Moscow. p. 253.

2. Mahkamov, Y. M., \& Mirzababaeva, S. M. (2020). Strength of bending reinforced concrete elements under action of transverse forces under influence of high temperatures. ACADEMICIA: An International Multidisciplinary Research Journal, 10(5), 618-624.

3. Makhkamov, Y.M., \& Mirzababayeva, S.M. (2019). Formation and development of cracks in bent reinforced concrete elements at high temperatures, their deformation and stiffness. Scientific and technical journal FerPI, (3), 160.160

4. Makhkamov, J.M., \& Mirzababayeva, S.M. (2019). Temperature deflections of reinforced concrete beams under the influence of technological temperatures. Problems of modern science and education, (11-1 (144)).

5. [Electronic resource]. Access mode: https://cyberleninka.ru/article/n/temper aturnye-progibyzhelezobetonnyh-balokv-usloviyah-vozdeystviya-

tehnologicheskih-temperatur/

(circulation date: 12.12.2019).

6. Milovanov, A.F., \& Pryadko, V.M. (1965). Calculation of bent reinforced concrete elements for a transverse force under conditions of high temperatures. Milovanov AF, Pryadko VM-Moscow: Stroyizdat., 1965, - 135 C.

7. Wiese J. (1983). Rechnerische Untersuchungen zum Tragund Verformungsverhalten brandbeanspruchter Stahlbetonplatten. Sonderforschungsbereich 148. Brandverhalten von Bauteilen. Technische Universitat Braunschweig. Arbeitsbericht 1981-1983. Teil 1. Braunschweig, , pp. 169-185.

8. Krampf L. (1981). Investigations on the shear behaviour of reinforced concrete beams exposed to fire. The Technic University of Brunswick, pp. 28.

9. KMK 2.03.04-98. (1998). Concrete and reinforced concrete structures designed for operation under conditions of elevated and high temperatures. T. p.115c. 